\title{
Case-control study of lifetime total physical activity and endometrial cancer risk
}

\author{
Christine M. Friedenreich • Linda S. Cook • \\ Anthony M. Magliocco • Máire A. Duggan • \\ Kerry S. Courneya
}

Received: 11 November 2009/Accepted: 8 March 2010/Published online: 25 March 2010

(C) The Author(s) 2010. This article is published with open access at Springerlink.com

\begin{abstract}
A population-based case-control study of physical activity and endometrial cancer risk was conducted in Alberta between 2002 and 2006. Incident, histologically confirmed cases of endometrial cancer $(n=542)$ were frequency age-matched to controls $(n=1,032)$. The Lifetime Total Physical Activity Questionnaire was used to measure occupational, household, and recreational activity levels. Multivariable logistic regression analyses were conducted. Total lifetime physical activity reduced endometrial cancer risk (odds ratio [OR] for $>129$ vs. $<82 \mathrm{MET}-\mathrm{h} /$ week/ year $=0.86,95 \%$ confidence interval $[95 \% \mathrm{CI}]: 0.63,1.18)$.
\end{abstract}

Electronic supplementary material The online version of this article (doi:10.1007/s10552-010-9538-1) contains supplementary material, which is available to authorized users.

C. M. Friedenreich $(\varangle) \cdot$ L. S. Cook

Alberta Health Services, 1331-29 St. N.W., Calgary,

AB T2N 4N2, Canada

e-mail: christine.friedenreich@albertahealthservices.ca

C. M. Friedenreich · A. M. Magliocco

Department of Oncology, University of Calgary, Calgary, AB, Canada

C. M. Friedenreich · L. S. Cook

Department of Community Health Sciences, University

of Calgary, Calgary, AB, Canada

L. S. Cook

Department of Internal Medicine, University of New Mexico, Albuquerque, NM, USA

\section{A. M. Magliocco - M. A. Duggan}

Department of Pathology and Laboratory Medicine,

University of Calgary, Calgary, AB, Canada

K. S. Courneya

Faculty of Physical Education and Recreation,

University of Alberta, Edmonton, AB, Canada
By type of activity, the risks were significantly decreased for greater recreational activity $(\mathrm{OR}=0.64,95 \% \mathrm{CI}: 0.47$, $0.87)$, but not for household activity $(\mathrm{OR}=1.09,95 \% \mathrm{CI}$ : $0.75,1.58)$ and/or occupational activity $(\mathrm{OR}=0.90,95 \%$ CI: $0.67,1.20$ ) when comparing the highest to lowest quartiles. For activity performed at different biologically defined life periods, some indication of reduced risks with activity done between menarche and full-term pregnancy and after menarche was observed. When examining the activity by intensity of activity (i.e., light $<3$, moderate $3-6$, and vigorous $>6$ METs), light activity slightly decreased endometrial cancer risk $(\mathrm{OR}=0.68,95 \%$ CI: $0.48,0.97)$ but no association with moderate or vigorous intensity activity was found. Endometrial cancer risk was increased with sedentary occupational activity by $28 \%$ (95 CI\%: $0.89,1.83$ ) for $>11.3 \mathrm{~h} /$ week/year versus $\leq 2.4 \mathrm{~h} /$ week/year or by $11 \%$ for every $5 \mathrm{~h} /$ week/year spent in sedentary behavior. This study provides evidence for a decreased risk between lifetime physical activity and endometrial cancer risk and a possible increased risk associated with sedentary behavior.

Keywords Case-control study - Cancer etiology · Endometrial neoplasms - Physical activity $\cdot$ Risk factors

\section{Introduction}

Endometrial cancer is the most common gynecologic cancer in Canada with an estimated 4,400 cases expected in 2009 and 800 deaths [1]. Several risk factors for the disease have been identified including obesity [2, 3], diabetes mellitus [4], family history of cancer [5], estrogen-only hormone replacement therapy [3, 6, 7], and various reproductive factors including nulliparity, early age at menarche, and late age at menopause [8]. Although less 
studied, some evidence suggests that physical activity may reduce the risk of endometrial cancer [9]. Among 24 previously conducted studies, 19 studies [10-28] suggested an inverse association of physical activity on endometrial cancer and a null association was reported in five studies [29-33]. A wide range of definitions of physical activity have been used in these studies, and none has systematically measured all types (i.e., occupational, household, recreational) and parameters (i.e., duration, frequency, and intensity) of physical activity performed throughout life. Recent reviews of this literature [9, 34] have emphasized the need for further research studies that have more detailed assessments of lifetime physical activity that consider all types and parameters of activity as well as activity done during different life periods and sedentary behavior as a separate risk factor. This study was specifically designed to address these gaps in previous studies of physical activity and its association with endometrial cancer risk.

\section{Materials and methods}

We conducted a population-based case-control study in Alberta, Canada between September 2002 and February 2006. This study received ethical approval, and all study subjects provided written informed consent before the interview. Incident, histologically confirmed invasive cases of endometrial cancer were identified directly from the Alberta Cancer Registry, a population-based cancer registry that has an estimated $95 \%$ case ascertainment rate [35]. Cases were eligible for the study if they were Alberta residents, aged 30-79, English-speaking, able to complete an in-person interview and self-administered diet questionnaire, and did not have another previous cancer except non-melanoma skin cancer. Permission to contact patients was sought through their referring physician. Once permission was obtained, in-person interviews were conducted. A total of 1,090 cases were identified and screened for eligibility and 900 were eligible, and physician approval to contact them was obtained for 808 women. A total of $552(68.3 \%)$ women completed the study interview, 249 declined participation (30.8\%), and $7(0.9 \%)$ could not be contacted. Three cases were excluded after re-review as they had complex atypical hyperplasia leaving 549 eligible for analysis.

Female controls were identified through random digit dialing using a pool of telephone numbers randomly generated from available prefixes for the province of Alberta. Controls were frequency matched to cases on age ( \pm 5 years) and were free of any cancer diagnosis excluding non-melanoma skin cancer. The telephone recruiters were able to screen $18,264(60.9 \%)$ of the 29,970 residences contacted and identified 1,998 eligible women, but $14(0.9 \%)$ could not be further contacted. Of the 1,984 eligible who were invited to participate, 948 (47.8\%) refused at screening or after receiving the study package, and the remaining $1,036(52.2 \%)$ completed the study interview. The final data set for analysis included 542 cases and 1,032 controls because seven cases and four controls were excluded because of unsatisfactory interviews.

\section{Data collection}

Respondents reported their personal health history, reproductive and menstrual history, exogenous hormone use history, family history of cancer, lifetime physical activity patterns, lifetime alcohol consumption history, smoking habits, demographic characteristics and usual adult height and weight at each decade from age 20 to 60 years. Information was ascertained through the reference date (the date of hysterectomy for the cases and a comparable date for the controls that was equivalent to the time difference between hysterectomy and date of interview for the cases). Diet in the year prior to the reference date was assessed with the National Cancer Institute's self-administered Diet History Questionnaire, previously adapted for use in Canada [36]. Interviews occurred on average $22(\mathrm{SD} \pm 11.5$ ) weeks after the participants' reference date with a range of 5-92 weeks with $72 \%$ completed within 6 months of diagnosis and $96 \%$ completed within 12 months of diagnosis.

A recall calendar focusing on major life events as well as a family history of cancer worksheet were mailed to the participants before the interview. This calendar, designed specifically for this study, was pilot-tested with the questionnaire and used as a means to improve respondent recall of lifetime physical activity. The interviewers used cognitive interviewing methods [37] to assist the respondents in answering the questions. Several quality control measures of the interviewers' methods were incorporated into the study design. The family history worksheet was used to report first and second degree relatives' history of cancer.

Lifetime physical activity was estimated using a questionnaire that had been tested for reliability [38], and used in previous case-control studies of breast and prostate cancers $[39,40]$. The reliability of total lifetime physical activity was estimated as 0.74 , and the correlation coefficients for occupational, household, and recreational activities were $0.87,0.77$, and 0.72 , respectively. This questionnaire assessed occupational, household, and recreational activities separately throughout a respondent's lifetime (from childhood to the reference date). The patterns of physical activity were recorded by the interviewer including the age started, aged ended, number of months per year, weeks per month, days per week and hours per day that each activity was performed so that the frequency and duration of these 
activities is determined. The participants also reported the intensity of their activity as sedentary (used for occupational activities only), light, moderate, or heavy (i.e., self-reported intensity). For occupational activity, we obtained job title as well as up to three descriptors of the actual activity performed at paid or volunteer occupational activities (e.g., standing, sitting, walking). Definitions for each intensity level by type of activity were provided with examples for the study participants. In addition to self-reported intensities, a specific MET value was assigned to each reported activity based on the description of the activity. The MET values used were abstracted from the Compendium of Physical Activities [41]. A MET is defined as the ratio of the associated metabolic rate for a specific activity when compared to the resting metabolic rate [42]. One MET is the average seated resting energy cost of an adult and is set at $3.5 \mathrm{~mL} / \mathrm{kg} / \mathrm{min}$ of oxygen. The variables estimated in this analysis were the average MET-hours per week per year spent in occupational, household, and recreational activity over the respondent's lifetime. Total lifetime physical activity was estimated as the sum of occupational, household, and recreational activity. At the end of the interview, interviewers used standardized methods to measure the study participants' current height, weight, and waist and hip circumferences.

\section{Statistical analysis}

Physical activity variables were categorized into quartiles according to the distribution of the variables among the controls. Odds ratios (ORs) and $95 \%$ confidence intervals (95\% CI) for endometrial cancer were estimated using unconditional logistic regression and a full assessment of confounding and effect modification was done. Univariate modeling was initially used to identify potential risk factors for endometrial cancer in these data. Variables considered as confounders were: age, education, menopausal status, age at menarche, body mass index (BMI) (weight/height ${ }^{2}$ ), waist circumference, parity, total fat intake, hormone contraception use, hypertension, hypercholesterolemia, and diabetes. Only those variables that were confounders in this data set or for which there was a biologic rationale were included in the final model. Determination of confounding was done by assessing both the association between the confounder and outcome and a change in risk effect. Final models were adjusted for age, BMI, waist circumference, age at menarche, hypertension, and parity. Models of each type of physical activity were adjusted for the other types of activity. Possible effect modification was assessed in this study by stratifying all models by menopausal status and BMI $\left(<25,25-30,>30 \mathrm{~kg} / \mathrm{m}^{2}\right)$. Histologic type (Type I and II) was assessed in sub-analyses. Tests for linear trend were performed for all models of categorized data by including the continuous, rather than the categorized, variable for each of the variables being modeled and all $p$ values reported are two-sided. The association between physical activity and endometrial cancer risk was examined in three sets of analyses. The first considered how risk was related to the type of physical activity, the second to the time period in life, defined by age groups and biologically relevant life periods, and the third to the dose (specifically the intensity, duration, and frequency) of activity. We also examined the risk associated with sedentary occupational behavior as a separate variable given the recent interest in sedentary behavior as a risk factor for chronic disease [43].

\section{Results}

In general, cases were less likely than controls to be parous and have a greater number of pregnancies, to be married or common-law, to have a university education, to have an older age at menarche, to use hormone contraception, and to use estrogen plus progesterone hormone therapy (Table 1). Conversely, cases were more likely than controls to have co-morbid conditions (high cholesterol/ triglycerides, diabetes, hypertension), to be overweight, and to have a greater waist-to-hip ratio. Cases were also slightly more likely to have used estrogen-only hormone therapy, but such exclusive use was uncommon and most use occurred prior to 5 years before the reference/diagnosis date in this population of women. A decreased risk of endometrial cancer was found for the women who were Caucasian, married or common-law and who had a university education. Likewise, early age at menarche decreased risk as did being parous and ever using hormones for contraception. Statistically significant increased endometrial cancer risks were found for increased waist circumference, being obese (BMI > 30), having a waist/ hip ratio above 0.88 , ever having hypertension, hypercholesterolemia/hyperglyceridemia, or diabetes. No increased risks were found for ever use of menopausal hormones, current smoking, alcohol, or fat intake.

The influence of total lifetime physical activity and each type of activity were examined as continuous (Table 1) and as categorized variables (Table 2). There was some indication of an inverse association between lifetime physical activity and endometrial cancer risk. For women in the highest quartile of lifetime total activity ( $>129.2$ MET-h/ week/year) compared to women in the lowest quartile ( $\leq 82.4 \mathrm{MET}-\mathrm{h} /$ week/year), the age-adjusted OR was 0.72 (95\% CI: $0.54,0.98), P_{\text {trend }}=0.03$. When we adjusted for confounding the risks became non-statistically significant in both the fully adjusted model $(\mathrm{OR}=0.92,95 \% \mathrm{CI}$ : $0.66,1.28$ ) or the model that did not include adjustment for BMI, waist circumference and hypertension 0.86 (95\% CI: 
Table 1 Description of the study population and age-adjusted odds ratios $(n=1,574)$, Alberta, Canada, 2002-2006

\begin{tabular}{|c|c|c|c|c|}
\hline Risk factor & Cases $(n=542)$ & Controls $(n=1,032)$ & $\mathrm{OR}^{\mathrm{a}}$ & $95 \% \mathrm{CI}^{\mathrm{a}}$ \\
\hline Age (years) & $58.7(9.3)^{\mathrm{a}}$ & $58.1(10.1)$ & N/A & - \\
\hline Ethnicity (Caucasian vs. non-Caucasian) & 95.0 & 95.9 & 0.76 & $0.46,1.26$ \\
\hline Ever married or common-law & 97.7 & 92.4 & 0.28 & $0.17,0.47$ \\
\hline \multicolumn{5}{|l|}{ Highest education } \\
\hline High school diploma & 32.7 & 28.2 & 1.00 & - \\
\hline Non-university certificate & 46.1 & 47.8 & 0.84 & 0.66 .1 .07 \\
\hline University degree & 21.2 & 24.1 & 0.77 & $0.58,1.04$ \\
\hline Age at menarche & $12.3(1.5)$ & $12.6(1.5)$ & 0.88 & $0.81,0.94$ \\
\hline Age at pregnancy of $\geq 20$ weeks gestation & $23.9(4.3)$ & $24.7(4.8)$ & 0.96 & $0.94,0.99$ \\
\hline \multicolumn{5}{|l|}{ Numbers of pregnancies $\geq 20$ weeks gestation } \\
\hline 0 & 18.1 & 10.3 & 1.00 & - \\
\hline $1-2$ & 43.4 & 41.5 & 0.57 & $0.41,0.78$ \\
\hline$>2$ & 38.6 & 48.3 & 0.40 & $0.28,0.55$ \\
\hline Age at menopause & $50.0(4.9)$ & $50.0(4.1)$ & 0.97 & $0.94,1.01$ \\
\hline \multicolumn{5}{|l|}{ Menopausal status } \\
\hline Premenopausal & 10.5 & 12.2 & 1.00 & - \\
\hline Perimenopausal & 12.7 & 15.6 & 0.96 & $0.62,1.50$ \\
\hline Postmenopausal & 76.6 & 72.9 & 1.29 & $0.82,2.03$ \\
\hline Body mass index [weight $(\mathrm{kg}) /$ height $\left.^{2}(\mathrm{~m})\right]$ & $32.1(8.3)$ & $28.1(5.9)$ & 1.09 & $1.07,1.11$ \\
\hline Waist circumference (per $1 \mathrm{~cm}$ ) & $98.0(18.8)$ & $87.6(14.6)$ & 1.04 & $1.03,1.05$ \\
\hline \multicolumn{5}{|l|}{ Waist/hip ratio [waist $(\mathrm{cm}) / \mathrm{hip}(\mathrm{cm})]$} \\
\hline$<0.80$ & 28.2 & 44.2 & 1.00 & - \\
\hline $0.80-0.88$ & 40.2 & 36.5 & 1.66 & $1.30,2.13$ \\
\hline$>0.88$ & 30.7 & 19.4 & 2.38 & $1.81,3.14$ \\
\hline \multicolumn{5}{|l|}{ Type of smoker } \\
\hline Never smoker & 50.4 & 50.9 & 1.00 & - \\
\hline Former smoker & 37.5 & 36.4 & 1.03 & $0.83,1.29$ \\
\hline Current smoker & 12.2 & 12.7 & 0.98 & $0.70,1.37$ \\
\hline Past year average total fat intake $(\mathrm{g} / \mathrm{day})^{\mathrm{b}}$ & $60.1(29.7)$ & $58.8(29.1)$ & 1.00 & $1.00,1.01$ \\
\hline Lifetime yearly alcohol consumption ( $\mathrm{g}$ of ethanol per year over lifetime) & $896.6(1,677.3)$ & $1,026.6(2,092.0)$ & 1.00 & $1.00,1.00$ \\
\hline Ever hormone contraception use & 60.5 & 70.8 & 0.63 & $0.50,0.79$ \\
\hline Never hormone replacement use ${ }^{c}$ & 55.6 & 49.8 & 1.00 & - \\
\hline Estrogen-only use ${ }^{c}$ & 3.7 & 2.4 & 1.31 & $0.71,2.42$ \\
\hline Estrogen and progesterone combined hormone use ${ }^{c}$ & 25.2 & 32.7 & 0.68 & $0.53,0.87$ \\
\hline Other hormone replacement use ${ }^{c}$ & 5.0 & 2.8 & 1.58 & $0.92,2.72$ \\
\hline Ever had high cholesterol or triglycerides & 33.4 & 26.8 & 1.35 & $1.07,1.70$ \\
\hline Ever had diabetes & 13.1 & 7.4 & 1.88 & $1.33,2.64$ \\
\hline Ever had hypertension & 42.4 & 26.2 & 2.12 & $1.69,2.66$ \\
\hline Total lifetime physical activity (MET-hours/week/year) & $104.0(36.8)$ & $107.3(36.5)$ & 1.00 & $0.99,1.00$ \\
\hline Total occupational activity (MET-hours/week/year) & $33.2(26.9)$ & $33.6(24.8)$ & 1.00 & $1.00,1.01$ \\
\hline Total household activity (MET-hours/week/year) & $58.7(27.1)$ & $60.6(28.0)$ & 1.00 & $0.99,1.00$ \\
\hline Total recreational activity (MET-hours/week/year) & $12.1(9.2)$ & $13.1(9.6)$ & 1.00 & $0.99,1.00$ \\
\hline Total lifetime physical activity (hours/week/year) & $32.7(10.5)$ & 33.8 (10.6) & 1.00 & $0.99,1.01$ \\
\hline
\end{tabular}

${ }^{a}$ Mean (standard deviation) or percentage

${ }^{\mathrm{b}}$ Eighty-seven women had missing dietary data because they either did not complete the questionnaire $(n=47)$ or their total caloric intake was $<600 \mathrm{kcal} /$ day or $>5,000 \mathrm{kcal} /$ day $(n=40)$

c All hormone replacement use categories included only perimenopausal or postmenopausal women ( $n=484$ cases and 905 controls) 
Table 2 Odds ratios for lifetime physical activity by type of activity $(n=1,574)$, Alberta, Canada, 2002-2006

\begin{tabular}{|c|c|c|c|c|c|c|c|c|}
\hline \multirow[t]{2}{*}{$\begin{array}{l}\text { Type of physical activity } \\
\text { quartile cutpoints (MET-h/week/year) }\end{array}$} & \multirow[t]{2}{*}{ Cases $(n=542)$} & \multirow[t]{2}{*}{ Controls $(n=1,032)$} & \multicolumn{2}{|c|}{ Age adjusted } & \multicolumn{2}{|c|}{$\begin{array}{l}\text { Multivariable } \\
\text { adjusted }^{\text {a }}\end{array}$} & \multicolumn{2}{|c|}{$\begin{array}{l}\text { Multivariable } \\
\text { adjusted }^{\text {b }}\end{array}$} \\
\hline & & & $\mathrm{OR}^{\mathrm{c}}$ & $95 \% \mathrm{CI}^{\mathrm{c}}$ & OR & $95 \% \mathrm{CI}$ & OR & $95 \% \mathrm{CI}$ \\
\hline \multicolumn{9}{|l|}{ Lifetime total physical activity } \\
\hline $0-\leq 82.4$ & 159 & 258 & 1.00 & - & 1.00 & - & 1.00 & - \\
\hline$>82.4-\leq 104.9$ & 135 & 258 & 0.82 & $0.62,1.10$ & 1.02 & $0.74,1.40$ & 0.94 & $0.70,1.28$ \\
\hline$>104.9-\leq 129.2$ & 126 & 258 & 0.76 & $0.57,1.02$ & 0.97 & $0.70,1.35$ & 0.89 & $0.65,1.21$ \\
\hline$>129.2$ & 122 & 258 & 0.72 & $0.54,0.98$ & 0.92 & $0.66,1.28$ & 0.86 & $0.63,1.18$ \\
\hline$P_{\text {trend }}$ & & & & 0.03 & & 0.57 & & 0.32 \\
\hline \multicolumn{9}{|l|}{ Lifetime occupational activity } \\
\hline $0-\leq 14.6$ & 165 & 258 & 1.00 & - & 1.00 & - & 1.00 & - \\
\hline$>14.6-\leq 29.2$ & 113 & 258 & 0.86 & $0.51,0.93$ & 0.71 & $0.51,0.97$ & 0.72 & $0.54,0.98$ \\
\hline$>29.2-\leq 46.9$ & 121 & 258 & 0.89 & $0.55,0.99$ & 0.80 & $0.59,1.10$ & 0.77 & $0.57,1.04$ \\
\hline$>46.9$ & 143 & 258 & 1.16 & $0.66,1.16$ & 0.81 & $0.60,1.11$ & 0.90 & $0.67,1.20$ \\
\hline$P_{\text {trend }}$ & & & & 0.41 & & 0.28 & & 0.52 \\
\hline \multicolumn{9}{|l|}{ Lifetime household activity } \\
\hline $0-\leq 40.5$ & 135 & 258 & 1.00 & - & 1.00 & - & 1.00 & - \\
\hline$>40.5-\leq 57.6$ & 151 & 258 & 1.07 & $0.79,1.44$ & 1.48 & $1.06,2.09$ & 1.34 & $0.97,1.86$ \\
\hline$>57.6-\leq 77.6$ & 138 & 258 & 0.96 & $0.70,1.30$ & 1.48 & $1.03,2.12$ & 1.35 & $0.96,1.90$ \\
\hline$>77.6$ & 118 & 258 & 0.79 & $0.57,1.10$ & 1.26 & $0.85,1.86$ & 1.09 & $0.75,1.58$ \\
\hline$P_{\text {trend }}$ & & & & 0.12 & & 0.35 & & 0.75 \\
\hline \multicolumn{9}{|l|}{ Lifetime recreational activity } \\
\hline $0-\leq 6.5$ & 170 & 258 & 1.00 & - & 1.00 & - & 1.00 & - \\
\hline$>6.5-\leq 10.5$ & 132 & 258 & 0.78 & $0.59,1.04$ & 0.85 & $0.62,1.15$ & 0.78 & $0.58,1.04$ \\
\hline$>10.5-\leq 16.9$ & 127 & 258 & 0.75 & $0.56,1.01$ & 0.80 & $0.58,1.09$ & 0.72 & $0.54,0.97$ \\
\hline$>16.9$ & 113 & 258 & 0.67 & $0.50,0.91$ & 0.81 & $0.59,1.12$ & 0.64 & $0.47,0.87$ \\
\hline$P_{\text {trend }}$ & & & & 0.01 & & 0.15 & & 0.004 \\
\hline
\end{tabular}

a Adjusted for age, body mass index, waist circumference, age at menarche, hypertension, and number of pregnancies of $\geq 20$ weeks gestation. Models of each type of activity were adjusted for the other types of activity

${ }^{\mathrm{b}}$ Same as ${ }^{\mathrm{a}}$ except no adjustment for BMI, waist circumference, and hypertension

c $O R$ odds ratio, $C I$ confidence interval

$0.63,1.11)$. When considering the risk associated by type of physical activity performed, a non-statistically significant reduced risk was observed with occupational activity $(\mathrm{OR}=0.81,95 \% \mathrm{CI}: 0.60,1.11)$, a slight increased risk existed for household activity (OR $=1.26,95 \%$ CI: 0.85 , 1.86 ), and a decreased risk with recreational activity $(\mathrm{OR}=0.81,95 \%$ CI: $0.59,1.12)$ that reached statistical significance in the multivariable model that was not adjusted for anthropometry and hypertension $(\mathrm{OR}=0.64$, $95 \% \mathrm{CI}: 0.47,0.87)$ and for which a dose-response was also noted $\left(P_{\text {trend }}=0.004\right)$.

We then examined how activity performed in different age and life period(s) was associated with endometrial cancer risk. No clear patterns of increased or decreased risk for any particular age (data not shown) or biologically relevant periods in life (Table 3) were observed for endometrial cancer. There was some suggestion that activity done between menopause and reference age might decrease endometrial risk for women particularly in the third quartile of total activity $(>93-\leq 131.2 \mathrm{MET}-\mathrm{h} /$ week/year) for whom a risk of 0.78 (95\% CI: $0.54,1.12)$ was observed. A similar decreased risk in the third quartile of activity was observed for activity done between birth and menarche $(\mathrm{OR}=0.77,95 \%$ CI: $56,1.06)$.

The question of how the dose of activity was associated with risk was examined in the next two analyses. The first examined risk by light, moderate, or vigorous levels of intensity $(<3,3-6$, and $>6$ METs) (Table 4$)$. A statistically significant reduced risk of endometrial cancer was found for light intensity activity (age-adjusted $\mathrm{OR}=0.56,95 \%$ CI: $0.40,0.76, P_{\text {trend }}=0.001$ ) for $>21.6 \mathrm{vs} .<11.1 \mathrm{~h} / \mathrm{week} /$ year) that remained statistically significant after full adjustment $\left(\mathrm{OR}=0.68,95 \% \mathrm{CI}: 0.48,0.97, P_{\text {trend }}=\right.$ 0.06). No reduced risk was observed with moderate intensity activity and for vigorous intensity activity there was only a slight risk reduction that was not statistically 
Table 3 Odds ratios for lifetime total physical activity by life periods $(n=1,574)$, Alberta, Canada, 2002-2006

\begin{tabular}{|c|c|c|c|c|c|c|}
\hline \multirow[t]{2}{*}{ Life period $^{\mathrm{c}}(\mathrm{MET}-\mathrm{h} /$ week/year $)$} & \multirow[t]{2}{*}{ Cases $(n=542)$} & \multirow[t]{2}{*}{ Controls $(n=1,032)$} & \multicolumn{2}{|c|}{ Age adjusted } & \multicolumn{2}{|c|}{ Multivariable adjusted $^{\mathrm{a}}$} \\
\hline & & & $\mathrm{OR}^{\mathrm{b}}$ & $95 \% \mathrm{CI}^{\mathrm{b}}$ & OR & $95 \% \mathrm{CI}$ \\
\hline \multicolumn{7}{|l|}{ Birth to menarche } \\
\hline $0-\leq 14.8$ & 142 & 258 & 1.00 & - & 1.00 & - \\
\hline$>14.8-\leq 22.7$ & 137 & 258 & 0.96 & $0.72,1.28$ & 1.02 & $0.75,1.40$ \\
\hline$>22.7-\leq 33.6$ & 113 & 258 & 0.79 & $0.58,1.07$ & 0.77 & $0.56,1.06$ \\
\hline$>33.6$ & 148 & 258 & 1.02 & $0.77,1.37$ & 1.05 & $0.77,1.43$ \\
\hline$P_{\text {trend }}$ & & & & 0.82 & & 0.76 \\
\hline \multicolumn{7}{|l|}{ Menarche to full-term pregnancy } \\
\hline $0-\leq 48.0$ & 118 & 226 & 1.00 & - & 1.00 & - \\
\hline$>48.0-\leq 66.8$ & 93 & 226 & 0.80 & $0.58,1.11$ & 0.78 & $0.55,1.10$ \\
\hline$>66.8-\leq 93.0$ & 114 & 226 & 0.97 & $0.71,1.33$ & 0.93 & $0.66,1.30$ \\
\hline$>93.0$ & 103 & 226 & 0.85 & $0.61,1.17$ & 0.82 & $0.58,1.16$ \\
\hline$P_{\text {trend }}$ & & & & 0.54 & & 0.43 \\
\hline \multicolumn{7}{|l|}{ Full-term pregnancy to menopause } \\
\hline $0-\leq 95.2$ & 91 & 167 & 1.00 & - & 1.00 & - \\
\hline$>95.2-\leq 129.6$ & 95 & 166 & 1.05 & $0.74,1.51$ & 1.17 & $0.80,1.71$ \\
\hline$>129.6-\leq 163.8$ & 73 & 167 & 0.82 & $0.56,1.19$ & 0.89 & $0.60,1.33$ \\
\hline$>163.8$ & 85 & 166 & 0.98 & $0.68,1.42$ & 1.10 & $0.74,1.63$ \\
\hline$P_{\text {trend }}$ & & & & 0.60 & & 0.97 \\
\hline \multicolumn{7}{|l|}{ Menopause to reference age } \\
\hline $0-\leq 59.7$ & 120 & 186 & 1.00 & - & 1.00 & - \\
\hline$>59.7-\leq 93.0$ & 109 & 185 & 0.92 & $0.66,1.28$ & 0.90 & $0.63,1.27$ \\
\hline$>93.0-\leq 131.2$ & 89 & 186 & 0.76 & $0.54,1.07$ & 0.78 & $0.54,1.12$ \\
\hline$>131.2$ & 95 & 185 & 0.82 & $0.58,1.15$ & 0.88 & $0.61,1.26$ \\
\hline$P_{\text {trend }}$ & & & & 0.15 & & 0.37 \\
\hline
\end{tabular}

${ }^{a}$ Adjusted for age, body mass index, waist circumference, age at menarche, hypertension, diabetes and number of pregnancies $\geq 20$ weeks gestation

b $O R$ odds ratio, $C I$ confidence interval

c Women who have not experienced a life event were excluded from any group that included that particular life event

significant. Subsequently, only the frequency and duration of the activities were considered (Table 5). There was some indication that doing over $3.7 \mathrm{~h} /$ week/year of recreational activity was associated with a decreased risk of endometrial cancer in the age-adjusted model $(\mathrm{OR}=0.73$, 95\% CI: 0.54, 0.99); however, this risk reduction was attenuated in the fully adjusted model and was no longer statistically significant $(\mathrm{OR}=0.86,95 \% \mathrm{CI}$ : 0.62, 1.19). Likewise, there was a decreased risk associated with occupational activity that was statistically significant in the second and third quartiles of activity where risks of 0.68 (95\% CI: $0.50,0.94)$ and 0.72 (95\% CI: 0.52, 0.99) were estimated. Conversely, there was an increased risk of endometrial cancer associated with each level of household activity above the referent quartile with the second and third quartiles associated with a 52-58\% increased risk that was statistically significant. A decreased risk for the highest quartile of total activity $(>47.7 \mathrm{~h} /$ week/year) was found for the age-adjusted model $(\mathrm{OR}=0.72(95 \% \mathrm{CI}$ : $0.84,1.57)$ that was not statistically significant and became attenuated in the multivariable model.

We also examined effect modification in this study by stratifying the study results by menopausal status and BMI. Only the results stratified by BMI are presented given the established strong association between obesity and endometrial cancer risk (Supplementary Table 1). There was some evidence for a stronger effect of physical activity among the most physically active, normal weight women $(\mathrm{BMI}<25)$ for whom a risk of 0.56 (95\% CI: 0.29, 1.08) was observed in the age-adjusted models that was, however, attenuated in the fully adjusted models $(\mathrm{OR}=0.81$, 95\% CI: $0.40,1.62)$.

We examined the effect of sedentary occupational activity separately (Table 6) as a risk factor for endometrial cancer and found a statistically significant increased risk among the women who spent the greatest amount of time 
Table 4 Odds ratios for lifetime total physical activity by intensity of activity ( $n=1,574)$, Alberta, Canada, 2002-2006

\begin{tabular}{|c|c|c|c|c|c|c|}
\hline \multirow{2}{*}{$\begin{array}{l}\text { Hours/week/year performed } \\
\text { at activity intensity level }\end{array}$} & \multirow[t]{2}{*}{ Cases $(n=542)$} & \multirow[t]{2}{*}{ Controls $(n=1,032)$} & \multicolumn{2}{|c|}{ Age adjusted } & \multicolumn{2}{|c|}{ Multivariable adjusted $^{\mathrm{a}}$} \\
\hline & & & $\mathrm{OR}^{\mathrm{b}}$ & $95 \% \mathrm{CI}^{\mathrm{b}}$ & OR & $95 \% \mathrm{CI}$ \\
\hline \multicolumn{7}{|c|}{ Light intensity activity (<3 METs) } \\
\hline $0-\leq 11.1$ & 158 & 258 & 1.00 & - & 1.00 & - \\
\hline$>11.1-\leq 16.0$ & 145 & 258 & 0.89 & $0.67,1.19$ & 0.97 & $0.71,1.32$ \\
\hline$>16.0-\leq 21.6$ & 145 & 258 & 0.87 & $0.66,1.17$ & 0.98 & $0.71,1.35$ \\
\hline$>21.6$ & 94 & 258 & 0.56 & $0.40,0.76$ & 0.68 & $0.48,0.97$ \\
\hline$P_{\text {trend }}$ & & & & 0.001 & & 0.06 \\
\hline \multicolumn{7}{|c|}{ Moderate intensity activity (3-6 METs) } \\
\hline $0-\leq 9.6$ & 143 & 258 & 1.00 & - & 1.00 & - \\
\hline$>9.6-\leq 15.3$ & 130 & 258 & 0.90 & $0.67,1.20$ & 0.89 & $0.65,1.23$ \\
\hline$>15.3-\leq 21.8$ & 123 & 258 & 0.84 & $0.62,1.14$ & 0.88 & $0.64,1.23$ \\
\hline$>21.8$ & 146 & 258 & 0.99 & $0.74,1.33$ & 1.02 & $0.74,1.43$ \\
\hline$P_{\text {trend }}$ & & & & 0.89 & & 0.89 \\
\hline \multicolumn{7}{|c|}{ Vigorous intensity activity ( $>6$ METs) } \\
\hline $0-\leq 0.06$ & 154 & 258 & 1.00 & - & 1.00 & - \\
\hline$>0.06-\leq 0.28$ & 137 & 258 & 0.90 & $0.67,1.19$ & 0.92 & $0.68,1.26$ \\
\hline$>0.28-\leq 0.75$ & 121 & 258 & 0.80 & $0.59,1.08$ & 0.85 & $0.62,1.17$ \\
\hline$>0.75$ & 130 & 258 & 0.87 & $0.64,1.16$ & 0.93 & $0.67,1.28$ \\
\hline$P_{\text {trend }}$ & & & & 0.25 & & 0.55 \\
\hline
\end{tabular}

${ }^{a}$ Adjusted for age, body mass index, waist circumference, age at menarche, hypertension, and number of pregnancies of $\geq 20$ weeks gestation. Models for each level of intensity of activity were adjusted for the other levels of intensity of activity

b $O R$ odds ratio, $C I$ confidence interval

being sedentary when compared to those in the lowest quartile of sedentary activity. A $42 \%$ increased statistically significant risk was observed in the age-adjusted model for women who spent $>11.3 \mathrm{~h} /$ week/year being sedentary in their occupations compared with women who spent $2.4 \mathrm{~h} /$ week/year or less being sedentary at work. This risk was attenuated in the fully adjusted model for which the $\mathrm{OR}=1.28(95 \%$ CI: $0.89,1.83)$. When modeled as a continuous variable, sedentary behavior increased endometrial cancer risk by $11 \%$ (95\% CI: $1.01,1.22)$ for every $5 \mathrm{~h} /$ week/year.

\section{Discussion}

Overall, an inverse association between total lifetime physical activity and endometrial cancer risk was observed. The risk reduction was attributable mainly to recreational physical activity for which a $36 \%$ statistically significant reduction in endometrial cancer was observed among women in the highest quartile of activity with a doseresponse effect across the categories observed as well. Physical activity done between menarche and full-term pregnancy and after menopause were associated with the greatest risk reductions that were, however, not statistically significant. Greatest benefit in terms of endometrial cancer risk reduction was observed for light intensity activities with no association found for moderate or vigorous intensity activities. When examining only the other parameters of dose of activity, i.e., duration and frequency, there were no clear increased or decreased risks for total activity or any individual type of activity with endometrial cancer. Of interest to note was the increased endometrial risk associated with sedentary occupational activity.

This study's results can be compared to the 24 previously conducted studies that included 12 cohort [10-20,29] and 12 case-control studies [21-28, 30-33]. A wide range of methods for physical activity assessment was used in these investigations and the definition of the highest category of activity in each study differed across studies. Of these 24 studies, $11[11,12,14,15,19,21,25-28,31]$ found a statistically significant decreased endometrial cancer risk for women who were the most active when compared to those least active, eight $[10,13,16-18,20,22,24]$ found a nonstatistically significant decreased risk and five studies [2933] observed no effect. When risk reductions are observed in these studies, the magnitude of the decrease is around $30 \%$. This risk reduction is in the same range as those estimated in a recent meta-analyses of physical activity in relation to colon [44] and breast cancers [45, 46].

None of the previous studies had a comprehensive measure of lifetime total activity. Eight studies [14, 21, 24, 
Table 5 Odds ratios for lifetime physical activity by type and dose of activity (frequency and duration only) $(n=1,574)$, Alberta, Canada, 2002-2006

\begin{tabular}{|c|c|c|c|c|c|c|}
\hline \multirow[t]{2}{*}{ Type of activity (hours/week/year) } & \multirow[t]{2}{*}{ Cases $(n=542)$} & \multirow[t]{2}{*}{ Controls $(n=1,032)$} & \multicolumn{2}{|c|}{ Age adjusted } & \multicolumn{2}{|c|}{ Multivariable adjusted $^{\mathrm{a}}$} \\
\hline & & & $\mathrm{OR}^{\mathrm{b}}$ & $95 \% \mathrm{CI}^{\mathrm{b}}$ & OR & $95 \% \mathrm{CI}$ \\
\hline \multicolumn{7}{|l|}{ Lifetime total physical activity } \\
\hline $0-\leq 26.3$ & 113 & 258 & 1.00 & - & 1.00 & - \\
\hline$>26.3-\leq 33.2$ & 159 & 258 & 0.87 & $1.03,1.87$ & 1.04 & $0.75,1.44$ \\
\hline$>33.2-\leq 40.9$ & 136 & 258 & 0.88 & $0.87,1.60$ & 1.16 & $0.83,1.61$ \\
\hline$>40.9$ & 134 & 258 & 0.72 & $0.84,1.57$ & 0.93 & $0.66,1.32$ \\
\hline$P_{\text {trend }}$ & & & & 0.70 & & 0.27 \\
\hline \multicolumn{7}{|l|}{ Lifetime occupational activity } \\
\hline $0-\leq 5.1$ & 124 & 258 & 1.00 & - & 1.00 & - \\
\hline$>5.1-\leq 9.9$ & 109 & 258 & 0.65 & $0.66,1.24$ & 0.68 & $0.50,0.94$ \\
\hline$>9.9-\leq 14.9$ & 135 & 258 & 0.66 & $0.84,1.54$ & 0.72 & $0.52,0.99$ \\
\hline$>14.9$ & 174 & 258 & 0.91 & $1.08,1.95$ & 0.89 & $0.66,1.21$ \\
\hline$P_{\text {trend }}$ & & & & 0.003 & & 0.13 \\
\hline \multicolumn{7}{|l|}{ Lifetime household activity } \\
\hline $0-\leq 13.8$ & 132 & 258 & 1.00 & - & 1.00 & - \\
\hline$>13.8-\leq 19.4$ & 151 & 258 & 1.09 & $0.81,1.47$ & 1.52 & $1.08,2.15$ \\
\hline$>19.4-\leq 25.6$ & 141 & 258 & 1.00 & $0.73,1.36$ & 1.58 & $1.10,2.29$ \\
\hline$>25.6$ & 118 & 258 & 0.81 & $0.58,1.13$ & 1.35 & $0.91,2.02$ \\
\hline$P_{\text {trend }}$ & & & & 0.17 & & 0.14 \\
\hline \multicolumn{7}{|l|}{ Lifetime recreational activity } \\
\hline $0-\leq 1.5$ & 148 & 258 & 1.00 & - & 1.00 & - \\
\hline$>1.5-\leq 2.3$ & 143 & 258 & 0.97 & $0.73,1.29$ & 1.01 & $0.74,1.38$ \\
\hline$>2.3-\leq 3.7$ & 144 & 258 & 0.98 & $0.74,1.31$ & 1.03 & $0.74,1.38$ \\
\hline$>3.7$ & 107 & 258 & 0.73 & $0.54,0.99$ & 0.86 & $0.62,1.19$ \\
\hline$P_{\text {trend }}$ & & & & 0.07 & & 0.40 \\
\hline
\end{tabular}

a Adjusted for age, body mass index, waist circumference, age at menarche, hypertension, and number of pregnancies of $\geq 20$ weeks gestation. Models for each level of intensity of activity were adjusted for the other levels of intensity of activity

${ }^{\mathrm{b}} O R$ odds ratio, $C I$ confidence interval

Table 6 Odds ratios for lifetime physical activity accounting for sedentary occupational activity $(n=1,574)$, Alberta, Canada, 2002-2006

\begin{tabular}{|c|c|c|c|c|c|c|c|c|}
\hline \multirow{2}{*}{$\begin{array}{l}\text { Type of physical activity } \\
\text { (hours/week/year) }\end{array}$} & \multirow[t]{2}{*}{ Cases $(n=542)$} & \multirow[t]{2}{*}{ Controls $(n=1,032)$} & \multicolumn{2}{|c|}{ Age adjusted } & \multicolumn{2}{|c|}{ Age and total activity ${ }^{\mathrm{c}}$} & \multicolumn{2}{|c|}{ Multivariable adjusted $^{a}$} \\
\hline & & & $\overline{\mathrm{OR}^{\mathrm{b}}}$ & $95 \% \mathrm{CI}^{\mathrm{b}}$ & OR & $95 \% \mathrm{CI}$ & OR & $95 \% \mathrm{CI}$ \\
\hline \multicolumn{9}{|c|}{ Lifetime occupational sedentary activity } \\
\hline $0-\leq 3.59$ & 123 & 258 & 1.00 & - & 1.00 & - & 1.00 & - \\
\hline$>3.59-\leq 9.26$ & 115 & 258 & 0.95 & $0.70,1.29$ & 0.92 & $0.68,1.26$ & 1.05 & $0.75,1.46$ \\
\hline$>9.26-\leq 16.94$ & 136 & 258 & 1.14 & $0.84,1.54$ & 1.09 & $0.80,1.48$ & 1.23 & $0.88,1.72$ \\
\hline$>16.94$ & 168 & 258 & 1.42 & $1.06,1.90$ & 1.29 & $0.92,1.79$ & 1.28 & $0.89,1.83$ \\
\hline$P_{\text {trend }}$ & & & & 0.009 & & 0.09 & & 0.12 \\
\hline Per 1 h/week/year & & & 1.03 & $1.01,1.04$ & 1.03 & $1.01,1.04$ & 1.02 & $1.00,1.04$ \\
\hline Per 5 h/week/year & & & 1.15 & $1.07,1.24$ & 1.14 & $1.04,1.24$ & 1.11 & $1.01,1.22$ \\
\hline
\end{tabular}

a Adjusted for age, body mass index, waist circumference, age at menarche, hypertension, and number of pregnancies of $\geq 20$ weeks gestation

b $O R$ odds ratio, $C I$ confidence interval

25, 28, 30-32] measured usual lifetime occupational activity or some aspect of recreational activity over lifetime rather than using current activity as a proxy for lifetime activity. Hence, the results of this study cannot be directly compared to any previous investigation. Nonetheless, for the studies that measured some aspect of usual 
or lifetime activity, decreased risks for either occupational and recreational activity were found in four studies [14, 21, $25,28]$ with no effect found in the remaining four studies [24, 30-32]. The investigations measuring usual or lifetime activity were less likely to observe an association with endometrial cancer risk, on the whole, than were the studies that assessed recent or baseline activity (as done in cohort studies). It is possible that our study and these previous ones [24, 30-32] were less able to observe an association because of measurement error in the assessment of physical activity. We have, however, found strong risk reductions for breast cancer [39, 47, 48] and modest reductions for prostate cancer [40] in association with lifetime physical activity as measured using this same instrument [38].

Only one previous study measured the frequency, duration, and intensity of the reported physical activity directly from the study participants [27] as we did in this study. Two early studies did not measure any parameter of the dose of activity performed [22, 29] and the remaining studies measured either one [10-12, 14, 15, 21, 23] or two $[13,16-20,26,28,30-33]$ of these parameters. Four studies have specifically examined and reported the association between endometrial cancer risk and vigorous intensity physical activity [13, 19, 27, 32]. In three of these studies [13, 19, 27, 32], risk reductions of 30-40\% were observed among women who were engaging in vigorous intensity activity at longer durations and/or frequencies. Our study, while not providing support for the suggestion that moderate or vigorous intensity activity is required for an endometrial cancer risk reduction, did nonetheless observe a risk decrease for activities done at a light intensity level with a statistically significant trend. In our study, the women were much more likely to have undertaken light intensity activity than vigorous intensity activities with most women achieving less than $1 \mathrm{~h} /$ week of vigorous intensity activity whereas most women accumulated at least $11 \mathrm{~h} /$ week of light intensity activity and the highest quartile was over $21 \mathrm{~h} /$ week. The highest quartile of vigorous activity in our study occurred at $45 \mathrm{~min}$ per week whereas public health guidelines suggest at least 75 min per week if engaging in vigorous activity [49]. Consequently, even the women in the highest quartile of vigorous activity in our study may have not been performing a sufficient amount of activity for endometrial cancer risk reduction. Our study participants were averaging $120 \mathrm{MET}-\mathrm{h} /$ week/year of total activity equivalent to $5.7 \mathrm{~h}$ of light (i.e., $\leq 3 \mathrm{MET}$ ) activity per day or $2.8 \mathrm{~h}$ of moderate daily activity ( $\leq 6 \mathrm{MET}$ ). This level is just above the minimum $150 \mathrm{~min}$ of weekly moderate intensity activity suggested in physical activity guidelines for chronic disease prevention [50] and well below the level of $420 \mathrm{~min} /$ week for cancer risk reduction [51].
Our results regarding an increased risk of endometrial cancer associated with sedentary behavior can be compared with three other studies that have also examined this risk factor [16, 18, 19]. Friberg et al. [16] found a statistically significant $66 \%$ increased endometrial cancer risk in a Swedish cohort study for women who watched television or sat for more than $5 \mathrm{~h}$ /day when compared to women with less than 5 h/day as sedentary. Patel et al. [18] in the Cancer Prevention Study-II Nutrition Cohort did not find any association between sitting time and endometrial cancer risk, and Gierach et al. in the NIH-American Association of Retired Persons Cohort Study observed a borderline statistically significant $23 \%$ increased risk with sitting more than $7 \mathrm{~h}$ /day versus less than $3 \mathrm{~h}$ daily sitting. Hence, our study results are within this range of previous findings since we observed a $42 \%$ increased risk in the age-adjusted model that was statistically significant for women who spent more than $11.3 \mathrm{~h} /$ week/year doing sedentary occupational activity. This risk was attenuated to a $28 \%$ non-statistically significant risk in the fully adjusted model, however, remained statistically significant when modeled as a continuous variable. For every $5 \mathrm{~h}$ /week/year of sedentary occupational activity, an $11 \%$ statistically significant increased risk was found. These four studies suggest that inactivity may be a strong risk factor for endometrial cancer that should be considered separately from activity in future studies.

An underlying biologic rationale exists to support an etiologic role for physical activity in endometrial carcinogenesis. At least three plausible mechanisms have been proposed to explain how activity influences endometrial cancer risk [34]. Physical activity could impact on endometrial cancer risk by decreasing endogenous estrogen levels, body fat, and improving insulin sensitivity [52]. These risk factors have all been associated with increased endometrial cancer risk [3, 6, 53]. While evidence exists to support these hypotheses, the exact biologic pathways that may be implicated remain unclear and need to be specifically examined in randomized controlled exercise intervention trials that incorporate biomarkers as intermediate endpoints. Moreover, by controlling for some of these possible mechanisms in our analyses, we may have attenuated the association between physical activity and endometrial cancer risk.

The limitations of this study need to be addressed. To begin, although this study was population-based, we had a lower response rate among the controls than among cases, which may have introduced a selection bias into our study results arising from a possible healthy volunteer bias. To address this concern, we compared the controls to a sample of women surveyed in Alberta as part of Statistics Canada's Community Health Survey (CCHS)[54]. The comparison was made with women of the same age and also living in Alberta, the response rate in the CCHS for Alberta was $77.4 \%$. Our study controls were generally 
similar to CCHS; however, they were more likely to be Caucasian (96 vs. $88 \%$ ), more educated (72 vs. $55 \%$ had greater than high school education), and ever married/ common-law (92 vs. $86 \%$ ). They were equally likely to have hypertension $(26.2$ vs. $23.5 \%)$, diabetes (7.4 vs. $6.5 \%$ ), to be smokers (49.1 vs. $51.4 \%$ ) and had nearly identical anthropometric characteristics (BMI: 28.1 vs. 27.8 ) and ages at menarche (12.6 vs. 13.1 years). The assessment of physical activity level in the present study is not comparable with the CCHS data, hence no direct comparison was possible. Based on these comparisons, no major selection bias is evident for our control population; however, it is acknowledged that there may be an underestimation of the inverse association between physical activity and endometrial cancer risk in our study because of selection bias.

The other sources of bias possible in this study are recall and misclassification bias. Since this study was retrospective and because we were interviewing women about 4 months after their cancer diagnosis and surgery, it is possible that they would have ruminated on their diagnosis and biased their responses to these questions. The possibility of such a bias being introduced into this study was reduced by including questions on numerous exposures and by not placing any particular emphasis on physical activity in this questionnaire. In addition, there had been limited public awareness of any association between physical activity and endometrial cancer at the time of data collection for this study. Misclassification bias could have occurred in this study since the respondents reported detailed lifetime physical activity patterns. The effect of misclassification of physical activity would have been to decrease the ability of the study to demonstrate an effect of physical activity on endometrial cancer risk. Since we observed relatively few associations between physical activity and endometrial cancer risk, this bias is a recognized possible limitation of these data. The strengths of our investigation include the comprehensive measure of lifetime total activity previously shown to be reliable, the large sample size, the complete assessment of confounding and effect modification, and the population-based study design. Our required sample size was 544 cases and 1,152 controls to detect a $30 \%$ risk reduction (i.e., $\mathrm{RR}=0.70$ ) associated with being physical active, which was an average risk reduction based on previous studies with $\alpha=0.05$ (twotailed) and $\beta=0.20$ ( $80 \%$ power). The achieved sample size was sufficiently large to detect the magnitude of risk reduction that we were expecting but measurement error and biases may have biased our results to the null.

Future studies would ideally include objective measurements of physical activity and inactivity since questionnaire methods on their own may not be sufficient to detect the associations between physical activity and endometrial cancer risk. Recently, significant progress has been made in developing a range of objective measurement methods that can be used to supplement the questionnaire-based reports of activity [55]. These objective methods, together with detailed records of all types and parameters of activity would provide more certainty regarding the exact nature of the role of physical activity in endometrial cancer etiology. Future research should also include other ethnic and racial groups since the associations may differ as has been found for breast cancer [46]. Our Alberta population was primarily Caucasian and relatively homogeneous with respect to education and marital status and underlying risks for endometrial cancer.

In summary, our study provides additional support for an etiologic role of lifetime physical activity in endometrial cancer risk as well as evidence for an increased risk with sedentary behavior. Together, the evidence that has accumulated suggests that physical activity may reduce risk of this cancer by one-third or more. Given that obesity is a well established risk factor for endometrial cancer and physical activity is a clear determinant of obesity, the role of physical activity in endometrial cancer etiology needs to be recognized and considered in future research.

Acknowledgments C. M. Friedenreich received career awards from the Canadian Institutes of Health Research and the Alberta Heritage Foundation for Medical Research (AHFMR). L. S. Cook and K. S. Courneya held Canada Research Chairs and L. S. Cook also received career award funding from AHFMR. Study design and initiation of data collection methods was done by Lisa Strosher and Pam Round. Rita Biel did study coordination with assistance by Aleata Ryhorchuk. Control recruitment was done by Colleen Lachance, Maryann Lester, Lisa Miller, Catherine Munro, and Polly Pratt. Subject interviews were done by Tamara Bellmont, Kay Christie, Pearl Cooke, Linda Davison, Carolyn Henderson, Tacey Lawrence, Rosalie Merkosky, Jodi Parrotta, Brenda Platzer, Cyndi Rasa, Nicole Slot, Keely Winnitoy, and Carol-Anne Zawalykut. Carla Quesnel did administrative tasks, and Holly Wilson identified cases from Calgary Laboratory Service pathology reports. Farit Vakhetov did data management, Jacquie Gregory initial data processing and preliminary analysis, and Thomas Speidel conducted the statistical analysis.

Conflict of interest statement This study was funded by grants from the National Cancer Institute of Canada with funding from the Canadian Cancer Society.

Open Access This article is distributed under the terms of the Creative Commons Attribution Noncommercial License which permits any noncommercial use, distribution, and reproduction in any medium, provided the original author(s) and source are credited.

\section{References}

1. Canadian Cancer Society, National Cancer Institute of Canada (2009) Canadian cancer statistics 2009. Canadian Cancer Society, National Cancer Institute of Canada, Toronto

2. Lindemann K, Vatten LJ, Ellstrom-Engh M, Eskild A (2009) The impact of BMI on subgroups of uterine cancer. Br J Cancer 101:534-536 
3. Kaaks R, Lukanova A, Kurzer MS (2002) Obesity, endogenous hormones, and endometrial cancer risk: a synthetic review. Cancer Epidemiol Biomarkers Prev 11(12):1531-1543

4. Lindemann K, Vatten LJ, Ellstrom-Engh M, Eskild A (2008) Body mass, diabetes and smoking, and endometrial cancer risk: a follow-up study. Br J Cancer 98(9):1582-1585

5. Gruber SB, Thompson WD (1996) A population-based study of endometrial cancer and familial risk in younger women. Cancer and Steroid Hormone Study Group. Cancer Epidemiol Biomarkers Prev 5(6):411-417

6. Akhmedkhanov A, Zeleniuch-Jacquotte A, Toniolo P (2001) Role of exogenous and endogenous hormones in endometrial cancer: review of the evidence and research perspectives. Ann N Y Acad Sci 943:296-315

7. Persson I (2000) Estrogens in the causation of breast, endometrial and ovarian cancers-evidence and hypotheses from epidemiological findings. J Steroid Biochem Mol Biol 74(5):357-364

8. McPherson CP, Sellers TA, Potter JD, Bostick RM, Folsom AR (1996) Reproductive factors and risk of endometrial cancer. The Iowa women's health study. Am J Epidemiol 143(12):1195-1202

9. Voskuil DW, Monninkhof EM, Elias SG, Vlems FA, van Leeuwen FE (2007) Physical activity and endometrial cancer risk, a systematic review of current evidence. Cancer Epidemiol Biomarkers Prev 16(4):639-648

10. Zheng W, Shu XO, McLaughlin JK, Chow WH, Gao YT, Blot WJ (1993) Occupational physical activity and the incidence of cancer of the breast, corpus uteri, and ovary in Shanghai. Cancer 71(11):3620-3624

11. Moradi T, Nyren O, Bergstrom R et al (1998) Risk for endometrial cancer in relation to occupational physical activity: a nationwide cohort study in Sweden. Int J Cancer 76(5):665-670

12. Terry P, Baron JA, Weiderpass E, Yuen J, Lichtenstein P, Nyren O (1999) Lifestyle and endometrial cancer risk: a cohort study from the Swedish Twin registry. Int J Cancer 82(1):38-42

13. Colbert LH, Lacey JV Jr, Schairer C, Albert P, Schatzkin A, Albanes D (2003) Physical activity and risk of endometrial cancer in a prospective cohort study (United States). Cancer Causes Control 14(6):559-567

14. Furberg AS, Thune I (2003) Metabolic abnormalities (hypertension, hyperglycemia and overweight), lifestyle (high energy intake and physical inactivity) and endometrial cancer risk in a Norwegian cohort. Int J Cancer 104(6):669-676

15. Schouten LJ, Goldbohm RA, van den Brandt PA (2004) Anthropometry, physical activity, and endometrial cancer risk: results from the Netherlands cohort study. J Natl Cancer Inst 96(21):1635-1638

16. Friberg E, Mantzoros CS, Wolk A (2006) Physical activity and risk of endometrial cancer: a population-based prospective cohort study. Cancer Epidemiol Biomarkers Prev 15(11):2136-2140

17. Friedenreich C, Cust A, Lahmann PH et al (2007) Physical activity and risk of endometrial cancer: the European prospective investigation into cancer and nutrition. Int J Cancer 121(2):347355

18. Patel AV, Feigelson HS, Talbot JT et al (2008) The role of body weight in the relationship between physical activity and endometrial cancer: results from a large cohort of US women. Int $\mathbf{J}$ Cancer 123(8): 1877-1882

19. Gierach GL, Chang SC, Brinton LA et al (2009) Physical activity, sedentary behavior, and endometrial cancer risk in the NIHAARP diet and health study. Int J Cancer 124(9):2139-2147

20. Conroy MB, Sattelmair JR, Cook NR, Manson JE, Buring JE, Lee IM (2009) Physical activity, adiposity, and risk of endometrial cancer. Cancer Causes Control 20(7):1107-1115

21. Sturgeon SR, Brinton LA, Berman ML et al (1993) Past and present physical activity and endometrial cancer risk. Br J Cancer 68(3):584-589
22. Levi F, La Vecchia C, Negri E, Franceschi S (1993) Selected physical activities and the risk of endometrial cancer. Br J Cancer 67(4):846-851

23. Hirose K, Tajima K, Hamajima N et al (1996) Subsite (cervix/ endometrium)-specific risk and protective factors in uterus cancer. Jpn J Cancer Res 87(9):1001-1009

24. Goodman MT, Hankin JH, Wilkens LR et al (1997) Diet, body size, physical activity, and the risk of endometrial cancer. Cancer Res 57(22):5077-5085

25. Moradi T, Weiderpass E, Signorello LB, Persson I, Nyren O, Adami HO (2000) Physical activity and postmenopausal endometrial cancer risk (Sweden). Cancer Causes Control 11(9):829-837

26. Salazar-Martinez E, Lazcano-Ponce EC, Lira-Lira GG et al (2000) Case-control study of diabetes, obesity, physical activity and risk of endometrial cancer among Mexican women. Cancer Causes Control 11(8):707-711

27. Littman AJ, Voigt LF, Beresford SA, Weiss NS (2001) Recreational physical activity and endometrial cancer risk. Am J Epidemiol 154(10):924-933

28. Matthews CE, Xu WH, Zheng W et al (2005) Physical activity and risk of endometrial cancer: a report from the Shanghai endometrial cancer study. Cancer Epidemiol Biomarkers Prev 14(4):779-785

29. Pukkala E, Poskiparta M, Apter D, Vihko V (1993) Life-long physical activity and cancer risk among Finnish female teachers. Eur J Cancer Prev 2(5):369-376

30. Dosemeci M, Hayes RB, Vetter R et al (1993) Occupational physical activity, socioeconomic status, and risks of 15 cancer sites in Turkey. Cancer Causes Control 4(4):313-321

31. Shu XO, Hatch MC, Zheng W, Gao YT, Brinton LA (1993) Physical activity and risk of endometrial cancer. Epidemiology 4(4):342-349

32. Olson SH, Vena JE, Dorn JP et al (1997) Exercise, occupational activity, and risk of endometrial cancer. Ann Epidemiol 7(1):4653

33. Tavani A, Bravi F, Dal ML et al (2009) Physical activity and risk of endometrial cancer: an Italian case-control study. Eur J Cancer Prev 18(4):303-306

34. Cust AE, Armstrong BK, Friedenreich CM, Slimani N, Bauman A (2007) Physical activity and endometrial cancer risk: a review of the current evidence, biologic mechanisms and the quality of physical activity assessment methods. Cancer Causes Control 18(3):243-258

35. Cancer in North America, 1991-1995 (1999) Volume one: incidence. North American Association of Cancer Registries, Sacramento, $\mathrm{CA}$

36. Csizmadi I, Kahle L, Ullman R et al (2007) Adaptation and evaluation of the National Cancer Institute's Dietary History Questionnaire and nutrient database for use in Canadian populations. Public Health Nutr 10(1):88-96

37. Willis GB (1994) Cognitive interviewing and questionnaire design: a training manual. Cognitive methods staff, working paper series No. 7. National Center for Health Statistics

38. Friedenreich CM, Courneya KS, Bryant HE (1998) The lifetime total physical activity questionnaire: development and reliability. Med Sci Sports Exerc 30(2):266-274

39. Friedenreich CM, Bryant HE, Courneya KS (2001) Case-control study of lifetime physical activity and breast cancer risk. Am J Epidemiol 154(4):336-347

40. Friedenreich CM, McGregor SE, Courneya KS, Angyalfi SJ, Elliott FG (2004) Case-control study of lifetime total physical activity and prostate cancer risk. Am J Epidemiol 159(8): 740-749

41. Ainsworth BE, Haskell WL, Whitt MC et al (2000) Compendium of physical activities: an update of activity codes and MET intensities. Med Sci Sports Exerc 32(9 suppl):S498-S504 
42. Anshell MH, Freedson P, Hamill J, Haywood K, Horwat M (1991) Dictionary of the sports and exercise sciences. Human Kinetics, Champaign, IL

43. Dunstan DW, Barr EL, Healy GN et al (2010) Television viewing time and mortality: the Australian diabetes, obesity and lifestyle study (AusDiab). Circulation 121(3):384-391

44. Wolin KY, Yan Y, Colditz GA, Lee IM (2009) Physical activity and colon cancer prevention: a meta-analysis. $\mathrm{Br} \mathrm{J}$ Cancer 100(4):611-616

45. Monninkhof EM, Elias SG, Vlems FA et al (2007) Physical activity and breast cancer: a systematic review. Epidemiology 18(1):137-157

46. Friedenreich CM, Cust AE (2008) Physical activity and breast cancer risk: impact of timing, type and dose of activity and population subgroup effects. Brit J Sports Med 42(8):636647

47. Friedenreich CM, Courneya KS, Bryant HE (2001) Influence of physical activity in different age and life periods on the risk of breast cancer. Epidemiology 12(6):604-612

48. Friedenreich CM, Courneya KS, Bryant HE (2001) Relation between intensity of physical activity and breast cancer risk reduction. Med Sci Sports Exerc 33(9):1538-1545
49. US Department of Health and Human Services (2008) Physical activity guidelines advisory committee report, 2008

50. Haskell WL, Lee IM, Pate RR et al (2007) Physical activity and public health: updated recommendation for adults from the American College of Sports Medicine and the American Heart Association. Circulation 116(9):1081-1093

51. World Cancer Research Fund and the American Institute for Cancer research (2007) Food, nutrition, physical activity, and the prevention of cancer: a global perspective. American Institute for Cancer Research, Washington, DC

52. Fair AM, Montgomery K (2009) Energy balance, physical activity, and cancer risk. Methods Mol Biol 472:57-88

53. Calle EE, Kaaks R (2004) Overweight, obesity and cancer: epidemiological evidence and proposed mechanisms. Nat Rev Cancer 4(8):579-591

54. Statistics Canada (2009) Canadian community health survey (CCHS) indicator profile, by age group and sex, canada, provinces, territories, health regions (2007 boundaries) and peer groups, annual, CANSIM (database)

55. Janz KF (2006) Physical activity in epidemiology: moving from questionnaire to objective measurement. $\mathrm{Br} \mathrm{J}$ Sports Med 40(3):191-192 